\title{
Role of age in association between gastric cancer and Helicobacter pylori eradication in cases with intestinal metaplasia and dysplasia
}

\author{
Ali Kabir ${ }^{1,2,3}$
}

Received: 31 January 2015/Accepted: 1 April 2015/Published online: 17 April 2015

(C) The International Gastric Cancer Association and The Japanese Gastric Cancer Association 2015

Keywords Age $\cdot$ Intestinal metaplasia $\cdot$ Gastric dysplasia

\section{Dear Editor,}

I read with interest the recent meta-analysis by Chen et al. [1]. They have presented very useful data. However, I am interested to know if they considered age as a covariate in their supplementary analyses, for example, using metaregression. This is because the ages of the different study groups which they entered in their meta-analysis are different, with wide a range, causing a misinterpretation. Maybe patients with intestinal metaplasia and dysplasia are older than their control group. We know that if the age is increased, the chance of reducing gastric cancer may not decrease despite eradication of Helicobacter pylori [2]. So, this nonsignificant difference between patients with intestinal metaplasia and dysplasia and the control group may be due to an age difference and not merely due to these diseases themselves.

\section{References}

1. Chen HN, Wang Z, Li X, Zhou ZG. Helicobacter pylori eradication cannot reduce the risk of gastric cancer in patients with intestinal metaplasia and dysplasia: evidence from a metaanalysis. Gastric Cancer. 2015. doi:10.1007/s10120-015-0462-7.

2. Shiotani A, Cen P, Graham DY. Eradication of gastric cancer is now both possible and practical. Semin Cancer Biol. 2013;23(6 Pt B):492-501.
Ali Kabir

aikabir@yahoo.com

1 Department of Epidemiology, School of Public Health, Shahid Beheshti University of Medical Sciences, Tehran, Iran

2 Center for Educational Research in Medical Sciences, Tehran University of Medical Sciences, Tehran, Iran

3 Nikan Health Researchers Institute, Unit 9, No. 1, 3rd Floor, 3rd Bahar Alley, Ashrafi Isfahani Highway, Poonak Square, Tehran, Iran 